\title{
Comparative assessment of heavy metals changes in the ambient air of two different zones of Tabriz city, Iran
}

\author{
Sabourmoghaddam N.* \\ Department of Environment and Natural Resources, Payame Noor University, P.O. Box 19395-3697 Tehran, Islamic Republic of Iran
}

Received: 16/04/2016, Accepted: 26/11/2016, Available online: 02/03/2017

*to whom all correspondence should be addressed:

e-mail: sabourmoghaddam@pnu.ac.ir

\begin{abstract}
Tabriz is a large and industrial city in the north west of Iran which suffers from severe air pollution due to being surrounded by mountains. Considering lack of official reports about the levels of heavy metals in Tabriz air, two zones of the city were selected for measurement of heavy metals in the air of this city. One of the two zones was located in a very heavy traffic zone of the city center, while the other was situated in a zone with relatively low levels of pollution. Three metals of lead, cadmium, and mercury were measured in these two zones. Among the three measured metals, lead with a concentration of $662 \mathrm{ng} \mathrm{m}^{-3}$ had the highest concentration, followed by cadmium and mercury with concentrations of 92 and $8 \mathrm{ng} \mathrm{m}^{-3}$ respectively. The concentrations of lead and cadmium in cold seasons were $30-50 \%$ greater than in warm seasons, whereas no significant correlation was observed between the concentration of mercury and the ambient temperature. No significant difference was observed between the concentrations of these metals in the two sampling sites; the levels of lead in winter in the city center were $20 \%$ greater than that in the countryside.
\end{abstract}

Key words: Lead, cadmium, mercury, air pollution

\section{Introduction}

One of the consequences of industrialization and the demand for improved quality of life has been increased exposure to air pollution. Heavy metals are among the most serious pollutants, coming from industrial activities, traffic and energy production (Vallero, 2014). Heavy metals such as lead, mercury, cadmium and nickel are normally found in air, but these heavy metals together with other pollutants, are discharged into the environment through industrial activities, automobile exhaust, electric power generators, municipal wastes and pesticides used in agriculture and can be taken up by human and animals from the environment through air and water.

Strict policies of governments on pollution-generating sources and improvement of fuels have resulted in gradual improvement of air quality in many cities of the world (Davis, 2008). However, in many regions of the world especially in Iran, due to inexpensiveness of the fuel and low quality of vehicles, air pollution to heavy metals in cities is still abundantly observed. Among heavy metals, lead, cadmium, mercury, and arsenic incur the greatest damage to the health of human beings (Jarup, 2003). These metals enter into human body through various means including digestive system (food and beverages), skin, or respiratory system, causing toxicity, side effects, and acute or chronic diseases in humans (Kampa and Castanas, 2008).

Tabriz with a population of over two million people is located in the northwest of Iran and is the capital of Eastern Azarbaijan. This city is the most important city of northwest of Iran, where in addition to urban vehicles a wide range of different factories have surrounded it. Due to lack of formal reports about the levels of heavy metal pollutants in Tabriz, this research has been an attempt to measure the level of these pollutants in two different zones of this city.

\section{Materials and methods}

\subsection{Sampling sites}

Tabriz is situated $1350 \mathrm{~m}$ above the sea level in the northwest of Iran (38:03N; 46:17E). This city is surrounded by Urmia Lake from the West and by mountains from the three other sides (Fig. 1). For the sampling, two sites were selected for measuring the pollution in Tabriz (Fig. 2). Site 1 named Rasteh Kucheh was located in the central zone of Tabriz and in the high-traffic zone. Due to proximity to the main market of the city and various commercial centers, municipality, and governmental offices it is very crowded and polluted. Site 2 called Hakim Nezami was situated in a residential area close to a park, only two kilometers away with the countryside. In the mentioned zones, heavy metal sampling instrument was placed two meter above the ground level.

\subsection{The procedure of collecting air samples}

Samplings were conducted in spring (May), summer (August), fall (November), and winter (February) in 20152016 in both sites simultaneously. Each time, the samples were collected for four days and each day for three hours using high-volume sampler (ET-VS-V1) with a flow rate of around $30 \mathrm{I} \mathrm{min}^{-1}$. To collect particles, fiberglass filter was employed. The samples of each day were individually 
recorded and transferred to laboratory. Together with sampling, air temperature was also recorded. To prevent the effect of high humidity and gust, sampling was carried out in non-rainy days with mild wind. Overall, for each experimental site, 16 samples, each of which containing a sample of 5400 I of air, were collected and then experimented in laboratory.
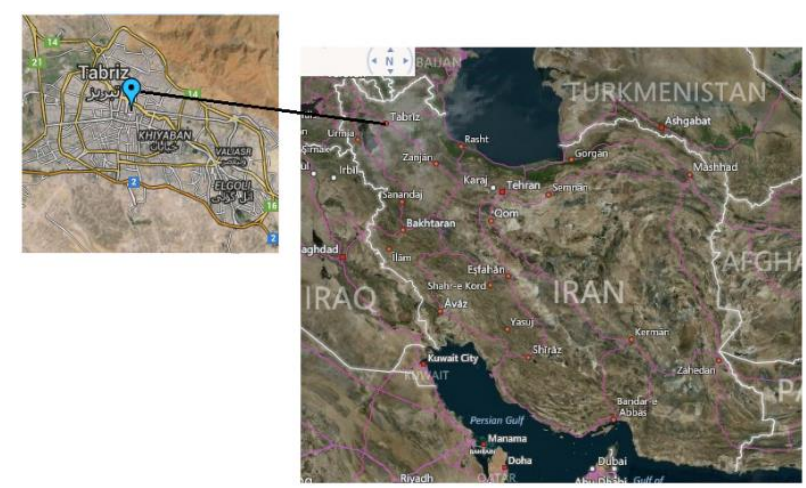

Figure 1. Location of Tabriz city in North-West Iran surrounded by mountains

\subsection{Measurement of heavy metals}

To calculate the level of heavy metals in the collected samples, atomic absorption spectrophotometer (AAS) (Varian Spectra Co, AA 220FS) was used. The wavelengths of 228.8, 253.7, and $283.3 \mathrm{~nm}$ were, respectively, used for measurement of cadmium (Cd), mercury $(\mathrm{Hg})$, and lead $(\mathrm{Pb})$.

\subsection{Preparation of the samples}

Samples were prepared using Melaku et al's method (2008) with minor modifications. Nitric acid $70 \%$ and $\mathrm{HCl} 30 \%$ were utilized for digestion of the filters. Deionized water was employed for extraction and making solutions of the samples. For each sample, $30 \mathrm{ml}$ nitric acid and $15 \mathrm{ml} \mathrm{HCl}$ were added to a beaker and then heated up to $100^{\circ} \mathrm{C}$. Once the solution's volume decreased by half in response to evaporation, distilled water was added to the solution. Following the filtration, the solution was redistilled so that the final volume of the solution would reach $10 \mathrm{ml}$.

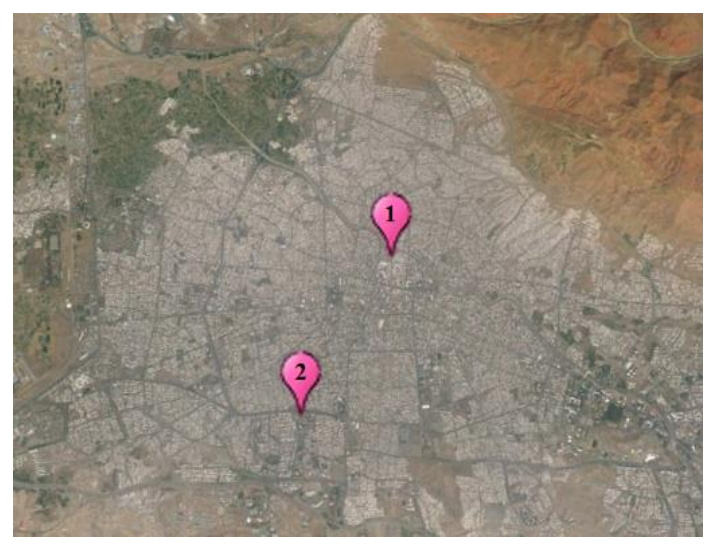

Figure 2. Location of sampling sites in the city of Tabriz

\section{Results}

The results of the analysis of air pollution in Tabriz to three metals of lead, cadmium, and mercury indicated that all of the three metals are present in the air of Tabriz. The levels of these three pollutants are summarized in Tables 1-3 as well as Diagrams 1-3. The mean concentration of lead, cadmium, and mercury in the samples was recorded to be 662,92 , and $8 \mathrm{ng} \mathrm{m}^{-3}$ of air respectively.

Table 1: The results of Lead $\left(\mathrm{ng} \mathrm{m}^{-3}\right)$ analysis in Tabriz air

\begin{tabular}{|c|c|c|c|c|}
\hline & Date & Factors & Site 1 & Site 2 \\
\hline & & Mean & $1019^{* *}$ & 803 \\
\hline & & SD* & 225 & 60 \\
\hline \multirow[t]{5}{*}{1} & February & Minimum & 925 & 785 \\
\hline & & Maximum & 1150 & 815 \\
\hline & & Temperature $\left({ }^{\circ} \mathrm{C}\right)$ & 9.00 & 8.00 \\
\hline & & Mean & 585 & 572 \\
\hline & & SD & 25 & 18 \\
\hline \multirow[t]{5}{*}{2} & May & Minimum & 585 & 562 \\
\hline & & Maximum & 610 & 580 \\
\hline & & Temperature $\left({ }^{\circ} \mathrm{C}\right)$ & 19.0 & 19.0 \\
\hline & & Mean & 512 & 507 \\
\hline & & SD & 02 & 05 \\
\hline \multirow[t]{5}{*}{3} & August & Minimum & 510 & 502 \\
\hline & & Maximum & 512 & 515 \\
\hline & & Temperature $\left({ }^{\circ} \mathrm{C}\right)$ & 34.0 & 31.0 \\
\hline & & Mean & 681 & 624 \\
\hline & & SD & 47 & 50 \\
\hline \multirow[t]{3}{*}{4} & November & Minimum & 655 & 605 \\
\hline & & Maximum & 702 & 655 \\
\hline & & Temperature $\left({ }^{\circ} \mathrm{C}\right)$ & 11.0 & 10.0 \\
\hline
\end{tabular}

*SD = standard deviation, ** $n g m^{-3}$ air

As can be seen in Table 1, the highest and lowest concentrations of lead were recorded in winter (February) and summer (August) with respective values of $1150 \mathrm{ng}$ and $502 \mathrm{ng} \mathrm{m}^{-3}$ of air. During the fall and winter, a 
significant difference was observed at 95\% level between the concentrations of lead in the air of the two sampling sites. While in warm seasons (spring and summer) this difference was not significant. A negative correlation was observed between increased temperature and the level of lead concentration in the air, where, the colder the ambient temperature, the higher the concentration of lead (Fig. 3). Across all stages of sampling, the concentration of lead in the first site (the polluted zone) was recorded to be on average $10 \%$ greater than in the second site (less polluted).

Considering the cadmium, across all stages of sampling, no significant difference was observed between the two sampling sites, but the metal's concentration in both sites was significantly higher in cold seasons (February and November) than in warm seasons (May and August) (Table 2) (Diagram 4). A significant negative correlation was observed between the environment temperature and the level of cadmium in the air. The maximum and minimum recorded concentrations for cadmium was $124 \mathrm{ng} \mathrm{m}^{-3}$ and $75 \mathrm{ng} \mathrm{m}^{-3}$ of air, in February and August, respectively. The results of mercury concentration revealed that this element is present at trace amounts $\left(8 \mathrm{ng} \mathrm{m}^{-3}\right)$ in the air of Tabriz (Table 3).

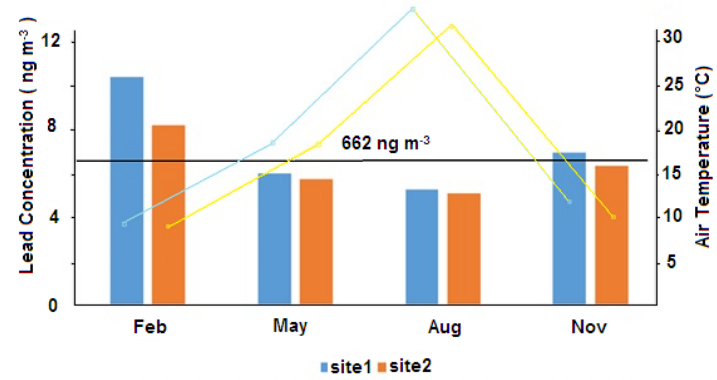

Figure 3. Seasonal variation of lead concentrations (bars; left vertical axis) and ambient temperature (lines; right vertical axis). The horizontal black line shows the annual lead concentration

Table 2. The results of Cadmium $\left(\mathrm{ng} \mathrm{m}^{-3}\right)$ analysis in Tabriz air

\begin{tabular}{|c|c|c|c|c|}
\hline & & & Site 1 & Site 2 \\
\hline \multirow{5}{*}{1} & \multirow{5}{*}{ February } & Mean & $120 * *$ & 117 \\
\hline & & SD* & 8.00 & 10.0 \\
\hline & & Minimum & 116 & 115 \\
\hline & & Maximum & 124 & 125 \\
\hline & & Temperature $\left({ }^{\circ} \mathrm{C}\right)$ & 9.00 & 8.00 \\
\hline \multirow{5}{*}{2} & \multirow{5}{*}{ May } & Mean & 89.0 & 87.0 \\
\hline & & SD & 10.0 & 15.0 \\
\hline & & Minimum & 85.0 & 76.0 \\
\hline & & Maximum & 95.0 & 90.0 \\
\hline & & Temperature $\left({ }^{\circ} \mathrm{C}\right)$ & 19.0 & 19.0 \\
\hline \multirow{5}{*}{3} & \multirow{5}{*}{ August } & Mean & 83.0 & 81.0 \\
\hline & & SD & 10.0 & 15.0 \\
\hline & & Minimum & 79.0 & 75.0 \\
\hline & & Maximum & 89.0 & 90.0 \\
\hline & & Temperature $\left({ }^{\circ} \mathrm{C}\right)$ & 34.0 & 31.0 \\
\hline \multirow{5}{*}{4} & \multirow{5}{*}{ November } & Mean & 98.0 & 97.0 \\
\hline & & SD & 12.0 & 10.0 \\
\hline & & Minimum & 91.0 & 91.0 \\
\hline & & Maximum & 103 & 101 \\
\hline & & Temperature $\left({ }^{\circ} \mathrm{C}\right)$ & 11.0 & 10.0 \\
\hline
\end{tabular}

*SD= standard deviation, ${ }^{* *} n g m^{-3}$ air

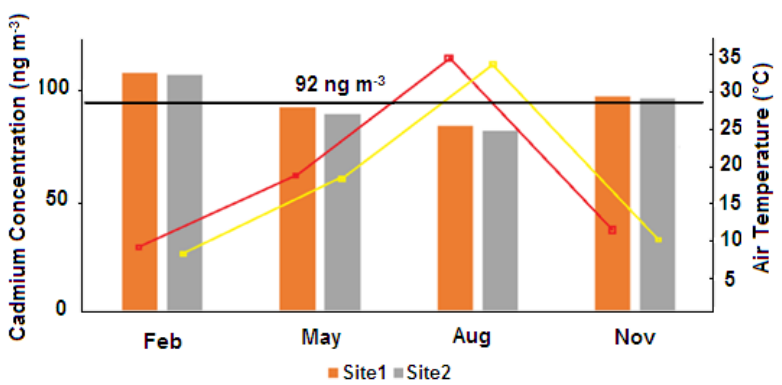

Figure 4. Seasonal variation of cadmium concentrations (bars; left vertical axis) and ambient temperature (lines; right vertical axis). The horizontal black line shows the annual cadmium concentration

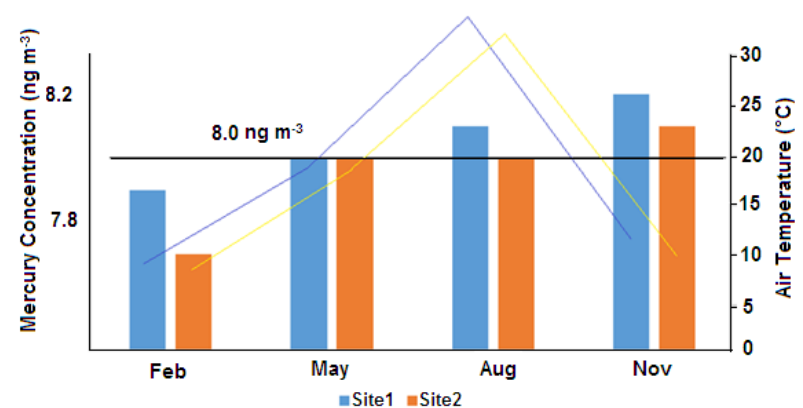

Figure 5. Seasonal variation of mercury concentrations (bars; left vertical axis) and ambient temperature (lines; right vertical axis). The horizontal black line shows the annual mercury concentration 
There was no significant differences between the concentrations of this heavy metal in both sampled zones. Moreover, unlike the two previous elements which had greater concentrations in cold seasons of the year, the concentration of this metal did not show any special correlation with temperature (Fig. 5). The maximum and minimum concentrations of mercury were observed in November and February with respective values of 9 and 7.2 $\mathrm{ng} \mathrm{m}^{-3}$ of air, respectively.

Table 3: The results of Mercury $\left(\mathrm{ng} \mathrm{m}^{-3}\right)$ analysis in Tabriz air

\begin{tabular}{|c|c|c|c|c|}
\hline & & & Site 1 & Site 2 \\
\hline & & Mean & $7.9 * *$ & 7.7 \\
\hline & & SD* & 1.1 & 0.2 \\
\hline \multirow[t]{5}{*}{1} & February & Minimum & 7.2 & 7.6 \\
\hline & & Maximum & 8.3 & 7.8 \\
\hline & & Temperature $\left({ }^{\circ} \mathrm{C}\right)$ & 9.0 & 8.0 \\
\hline & & Mean & 8.0 & 8.0 \\
\hline & & SD & 1.0 & 0.10 \\
\hline \multirow[t]{5}{*}{2} & May & Minimum & 7.5 & 7.9 \\
\hline & & Maximum & 8.5 & 8.0 \\
\hline & & Temperature $\left({ }^{\circ} \mathrm{C}\right)$ & 19.0 & 19.0 \\
\hline & & Mean & 8.1 & 8.0 \\
\hline & & SD & 0.1 & 0.5 \\
\hline \multirow[t]{5}{*}{3} & August & Minimum & 8.0 & 7.7 \\
\hline & & Maximum & 8.2 & 8.2 \\
\hline & & Temperature $\left({ }^{\circ} \mathrm{C}\right)$ & 34.0 & 31.0 \\
\hline & & Mean & 8.2 & 8.1 \\
\hline & & SD & 1.0 & 0.4 \\
\hline \multirow[t]{3}{*}{4} & November & Minimum & 8.0 & 7.8 \\
\hline & & Maximum & 9.0 & 8.2 \\
\hline & & Temperature $\left({ }^{\circ} \mathrm{C}\right)$ & 11.0 & 10.0 \\
\hline
\end{tabular}

*SD= standard deviation, **ng $m^{-3}$ air

\section{Discussion}

The concentration of the three heavy metals including lead, cadmium, and mercury were measured in two different sites in Tabriz. These heavy metals are among the most common environmental pollutants in most polluted areas of the world. They can enter into the physiological systems of human beings and animals through air or respiratory system, thereby causing various diseases (Vallero, 2014). Based on the standards of United States Environmental Protection Agency (EPA), the standard level of lead in fresh air is $1.5 \mu \mathrm{g} \mathrm{m}^{-3}$, and the maximum limit of lead in working environments has been considered to be around $50 \mu \mathrm{g} \mathrm{m}^{-3}$ for $8 \mathrm{~h}$ of work (EPA, 2015a).

The major sources of lead in the atmosphere of the cities are the combustion of leaded gasoline in vehicles and airplanes as well as fume of factories. Fortunately, currently by replacing gasoline containing lead with leadfree gasoline, its level has decreased in many cities around the world including Iran (Saha and Kim, 2013; Sarrafpour et al., 2007). Although no previous information is available about the levels of lead in Tabriz air, in this research the concentration of lead in air of Tabriz was recorded to be below the acceptable standards, according to Table 1, though this value is still high. In the US, according to Agency for Toxic Substances and Disease Registry, the acceptable level of lead in urban air has been decreased to $0.2 \mu \mathrm{g}$ or $200 \mathrm{ng} \mathrm{m}^{-3}$ (ATSDR, 2015b, EPA; 2015b). Based on this, the level of lead in Tabriz air is three times greater than the new standards. When compared to other cities in Iran, the status of Tabriz does not seem to be very favorable, since the research done in Tehran and Mashhad that are more populated than Tabriz suggests that the concentration of lead in those two cities is lower than that in Tabriz (Moattar et al., 2012; Sarrafpour et al., 2007). The high concentration of lead in Tabriz can be due to being surrounded by mountains and lack of possibility for pollutants to move away from zones off the city. As can also be observed in Fig. 2, Tabriz is surrounded by high mountains from three sides. On the other hand, the majority of large industrial factories, refineries, and petrochemical factories are constructed in the west of Tabriz. Moreover, considering the direction of wind in the city, mostly from west to east, in addition to intracity pollutants - including the fume of vehicles and household heating systems - the city is subjected to industrial pollutants from its suburbs, and despite wind proneness of the city, this accounts for the high level of air pollution in this city.

With respect to cadmium and mercury, although the situation was better and both were below the official standards, these metals are still polluting Tabriz air. The acceptable level for cadmium and mercury in the air has been reported to be 150 and $300 \mathrm{ng} \mathrm{m}^{-3}$, respectively (EPA, 2015 c, d). In Tabriz, this level has been recorded to be 92 and $8 \mathrm{ng}$, which is below the reported standards for both of the registered concentrations. Few changes were observed for the concentration of mercury during the year, with $10 \%$ difference between the minimum and maximum measured levels during the year. In contrast, for cadmium, 
this difference was around $100 \%$. Melaku et al (2008) also showed that the concentration of cadmium is variable during the year, with dramatic fluctuations during various seasons. Considering the lead and cadmium, the concentration measured in cold months (February and November) was greater than in warm months. Saha and Kim also demonstrated that the concentration of cadmium in cold seasons is far greater than in warm seasons. The phenomenon of inversion and stability of air is a common issue in cold seasons of the year, resulting in accumulation of pollutants in the city and unnatural elevation of air pollution. Based on numerous reports about air inversion in Iran's cities, this growth in the concentration of lead and cadmium during cold seasons is justifiable.

Vijayanand et al., (2008) analysed suspended particulate matter for heavy metals and revealed the presence of metallic constituents such as $\mathrm{Cu}, \mathrm{Zn}, \mathrm{Pb}, \mathrm{Cd}, \mathrm{Ni}$ and Fe. The concentration of $\mathrm{Pb}$ in SPM at all sampling sites were ranged between 0.21 and $0.62 \mathrm{~g} \mathrm{~m}^{-3}$ and they could not find any positive correlation between the concentrations of $\mathrm{Pb}$ and that of SPM. However, in spite of more than 300 electroplating units in and around the Coimbatore city and of heavy automobile traffic, $\mathrm{Cd}$ was not detected in all the representative sampling stations.

\section{Conclusion}

The study carried out to measure the concentration of lead, cadmium, and mercury in the air of two selected sites of Tabriz city. Even though these three metals were found in air of city but they were below the acceptable standards. Considering these rates of heavy metal contents, regular survey at appropriate intervals from different parts of city for monitoring the quality of air in this city is highly recommended.

\section{Acknowledgments}

This work was supported by a research grant from the Payame Noor University, Tehran, Iran. The author appreciates the colleagues in Microbiology Lab (Faculty of Agriculture-University of Tabriz) for their great support.

\section{References}

ATSDR, (2015), Toxicological Profile for Heavy Metal. (http://www.atsdr.cdc.gov/toxprofiles/tp5.pdf).

Davis, L.W. (2008), The effect of driving restrictions on air quality in Mexico City, Journal of Political Economy, 116, 38-81.

EPA, (2015a), Lead: Human Exposure and Health Risk Assessments for Selected Case Studies, 172 pages.

EPA, (2015b), National Trends in Lead Levels. (http://www3.epa.gov/airquality/airtrends/lead.html).

EPA, (2015c), Cadmium Compounds; Hazard Summary. (http://www3.epa.gov/airtoxics/hlthef/cadmium.html)

EPA, (2015d), Mercury and Air Toxics Standards (MATS). (http://www3.epa.gov/mats/actions.html)

Kampa M. and Castanas E. (2008), Human health effects of air pollution, Environmental pollution, 151, 362-367.

Järup L. (2003), Hazards of heavy metal contamination, British medical bulletin, 68, 167-182.

Melaku S., Morris V., Raghavan D. and Hosten C. (2008), Seasonal variation of heavy metals in ambient air and precipitation at a single site in Washington, DC, Environmental Pollution, 155, 88-98.

Moattar F., Mikhchi K., Muhammad Zadeh A., Karbasi A.B. and Delbari A. (2012), Evaluation of Heavy metal concentration in Iran atomic organization area, Journal of Environmental Sciences and Technology, 14, 29-38 (in Persian).

Saha S.K. and Kim K.H. (2013), Long-Term Variations of Airborne Cadmium (Cd) Concentrations in Major Urban Areas of Korea between 1991 and 2010, Aerosol and Air Quality Research, 13, 1078-1089.

Sarrafpour R., Abadi Sh., Pourvali F. and Roozbahani F. (2007), Lead Concentration in Region No.1 of Tehran, Journal of Environmental Sciences and Technology, 11, 93-106, (in Persian).

Vallero D. (2014), Fundamentals of air pollution. $5^{\text {th }}$ edition, Academic press, 986Pp.

Vijayanand C., Rajaguru P., Kalaiselvi K., Selvam K.P. and Palanivel M. (2008), Assessment of heavy metal contents in the ambient air of the Coimbatore city, Tamilnadu, India, Journal of Hazardous Materials, 160, 548-553. 